\title{
High Speed and Long Reach DPSK-OFDM-Is-OWC under Impact of Space Turbulences
}

\author{
Abhishek Sharma \\ Assistant Professor \\ Sri Sai University \\ Palampur, India
}

\author{
Vishal Kumar \\ Research Scholar \\ Sri Sai University \\ Palampur, India
}

\author{
Chandni \\ Assistant Professor \\ Sri Sai University \\ Palampur, India
}

\begin{abstract}
Inter-satellite communication is a free-space optical technology which is used to establish communication between satellites in space. This work is focused on the transmission of 10 Gbps data over 10,000 km inter-satellite communication link by incorporating orthogonal frequency division multiplexing scheme. The performance of proposed system is evaluated in terms of signal-to-noise ratio, total received power, radio-frequency spectrum and constellation diagrams.
\end{abstract}

\section{Keywords}

Inter-satellite communication (Is-OWC), Orthogonal frequency division multiplexing (OFDM), Differential phase shift key (DPSK).

\section{INTRODUCTION}

In early 1960's, Laser technology was gaining its popularity in the field of optical communication and finding its applications for communication between satellite and earth station as well as submarines[1]. Numerous advantages of laser such as higher band width, minimal power requirements, marginal electro-magnetic interference (EMI) encouraged it's application in radio frequency (RF) technology [2, 3]. Laser being coherent finds its application in free space communication known as Optical Wireless Communication (OWC) and further was used for communication between satellites more commonly known as Inter Satellite Optical Wireless Communication (Is-OWC). In Is-OWC, the information signal is modulated over laser light and transmitted to other orbiting satellites using Free Space Optics. These satellites may be orbiting in the same or in different orbit. At receiving satellites, received signal are demodulated using photodiodes and thus original signal is recovered [4-7]. In OWC, Orthogonal Frequency Division Multiplexing (OFDM) technology has played an vital role for it capacity in reducing multipath fading effects [8-16]. OFDM uses subcarriers which are separated by specific frequencies of overlapping band for data transportation. Further for orthogonal sequence, these subcarriers utilize Fast Fourier Transformation (FFT) $[17,18]$. Thus OFDM is used for high data transmission and lower fading impacts [19-21]. Though the vacuum is assumed to be perfect, path loss which increases as square $f$ the distance is huge. Further Is-OWC links are sensitive for pointing errors which may arise due to misalignment, vibrations or tracking errors [22-35][2-12]. In our work OFDM-DPSK-Is-OWC system is designed to transmit $10 \mathrm{Gbps}$ data over a distance of $10,000 \mathrm{Km}$ under the impact of turbulence. The rest of the paper is divided as follows: Section 2 explains the system description; Section 3 presents the results and discussion followed by Section 4 which provides the conclusion.

\section{SYSTEM DESCRIPTION}

The performance of proposed DPSK-OFDM-Is-OWC link is evaluated under the impact of space turbulences in OptiSystem software. Figure 1 shows the schematic diagram of proposed system under the impact of space turbulences. The space turbulences are considered as transmitting pointing errors and receiving pointing errors. The simulation is carried out from $1 \mu \mathrm{rad}$ to $5 \mu \mathrm{rad}$ transmitting pointing error and 1 $\mu \mathrm{rad}$ to $5 \mu \mathrm{rad}$ receiving pointing error.

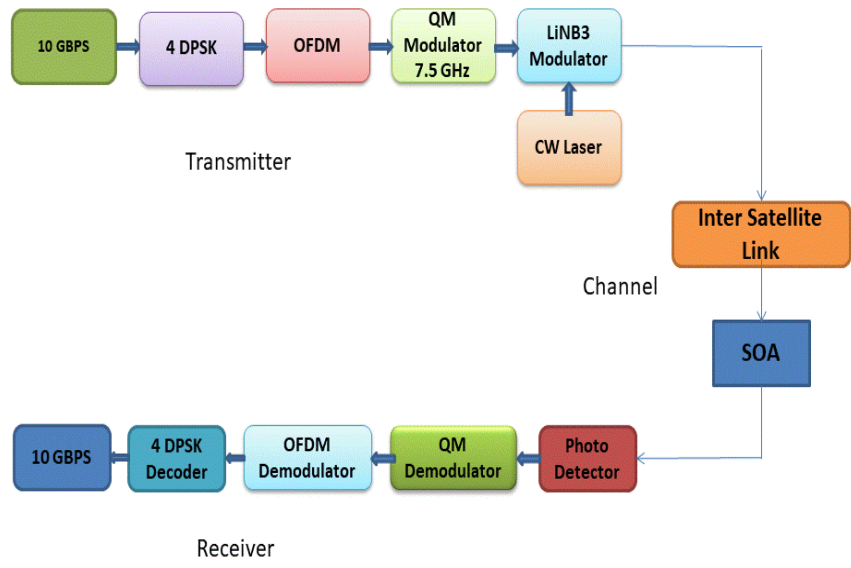

Fig 1: DPSK-OFDM-Inter-Satellite Communication System under Space Turbulences

\section{RESULTS AND DISCUSSION}

In this section, results obtained from the simulation of proposed 10 Gbps DPSK-OFDM-Is-OWC system over 10000 $\mathrm{km}$ Is-OWC link under the impact of transmitting pointing errors and receiving pointing errors are presented and discussed. Figure 2 shows the measured SNR for proposed system with $-4 \mathrm{dBm}$ power and $0 \mathrm{dBm}$ power under the impact of transmitting pointing errors. The value of SNR for system with $-4 \mathrm{~dB}$ input power is noted as $31.83 \mathrm{~dB}, 14.21 \mathrm{~dB}$ and 0 at transmitting pointing error of $1 \mu \mathrm{rad}, 3 \mu \mathrm{rad}$ and 5 $\mu \mathrm{rad}$ whereas for the system with $10 \mathrm{~dB}$ input power it is noted as $38.91 \mathrm{~dB}, 35.69 \mathrm{~dB}$ and 0 at transmitting pointing error of $1 \mu \mathrm{rad}, 3 \mu \mathrm{rad}$ and $5 \mu \mathrm{rad}$. This shows that improvement of $8 \mathrm{~dB}$ in SNR is noticed when input power is increased from $-4 \mathrm{dBm}$ to $10 \mathrm{dBm}$. Similarly Figure 3 shows measured total received power under the impact of transmitting pointing error. 


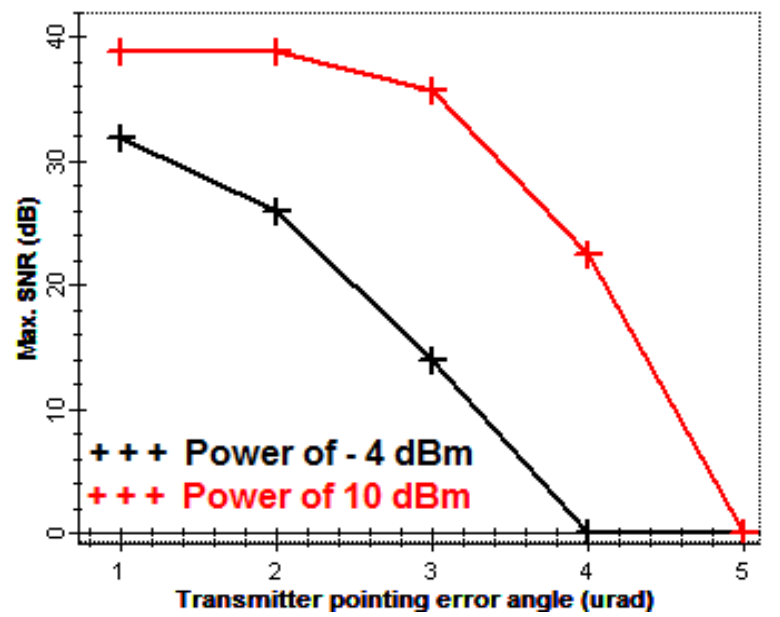

Fig 2: Measured SNR under the impact of transmitting pointing error

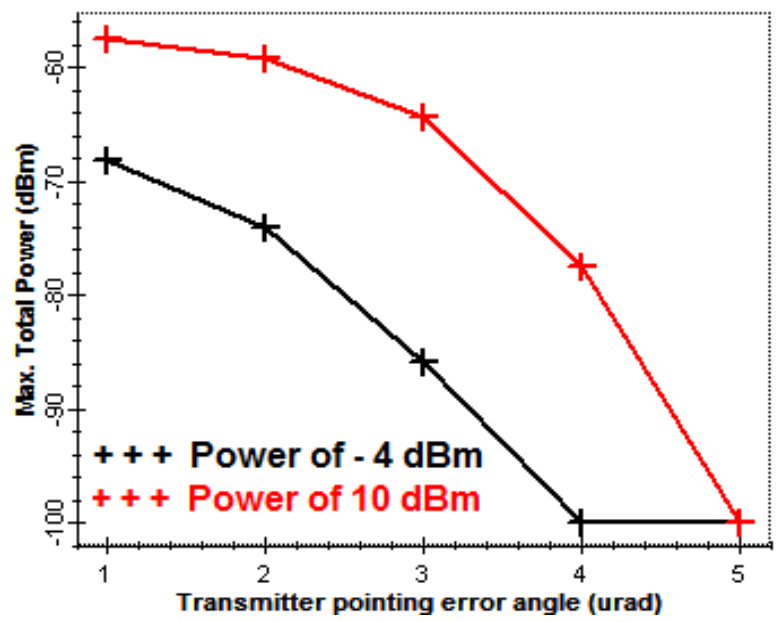

Fig 3: Measured Total received power under the impact of space turbulences

The value of total received power for system with $-4 \mathrm{~dB}$ input power is noted as $-68.11 \mathrm{dBm},-84.98 \mathrm{dBm}$ and $-100 \mathrm{dBm}$ at transmitting pointing error of $1 \mu \mathrm{rad}, 3 \mu \mathrm{rad}$ and $5 \mu \mathrm{rad}$ whereas for the system with $10 \mathrm{~dB}$ input power it is noted as $57.11 \mathrm{dBm},-64.32 \mathrm{dBm}$ and $-100 \mathrm{dBm}$ at transmitting pointing error of $1 \mu \mathrm{rad}, 3 \mu \mathrm{rad}$ and $5 \mu \mathrm{rad}$. This shows that improvement of $-10 \mathrm{dBm}$ in total received power is noticed when input power is increased from $-4 \mathrm{dBm}$ to $10 \mathrm{dBm}$.

Figure 4 and 5 shows the measured constellations and RF spectrums under the impact of transmitting pointing error with input power of $10 \mathrm{dBm}$. The clear constellations and RF spectrum shows the successful transmission of data over $10000 \mathrm{~km}$ Is-OWC link under impact of $4 \mu \mathrm{rad}$ transmitting pointing error. Beyond that value, the proposed system shut downs.

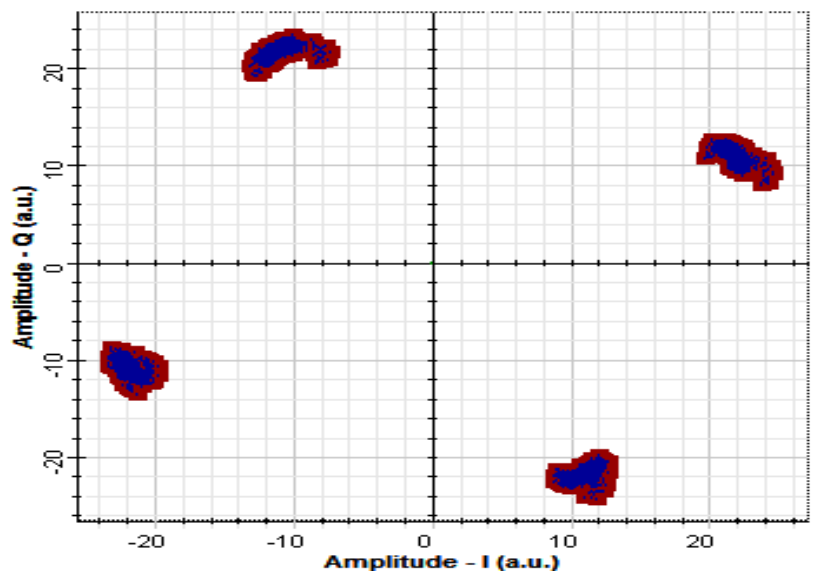

(a)

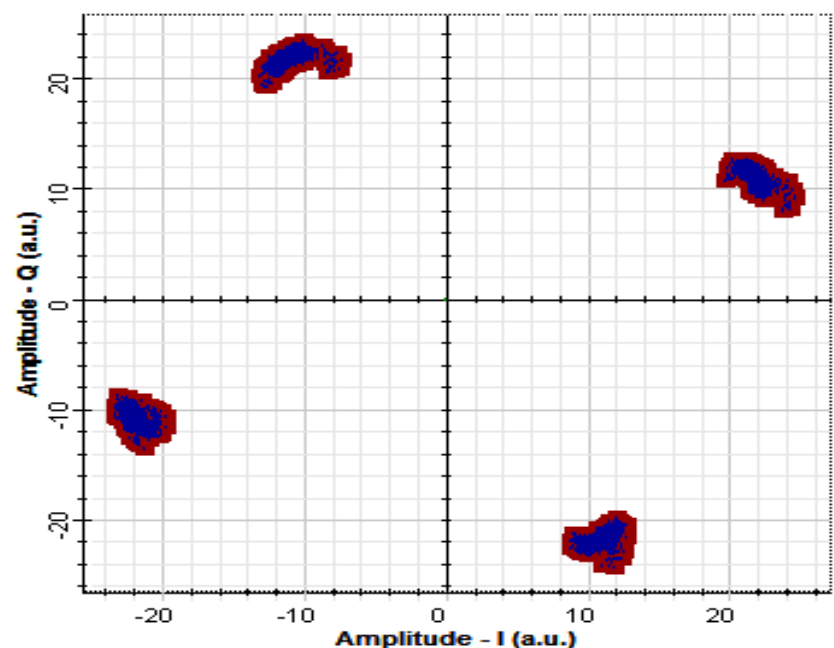

(b)

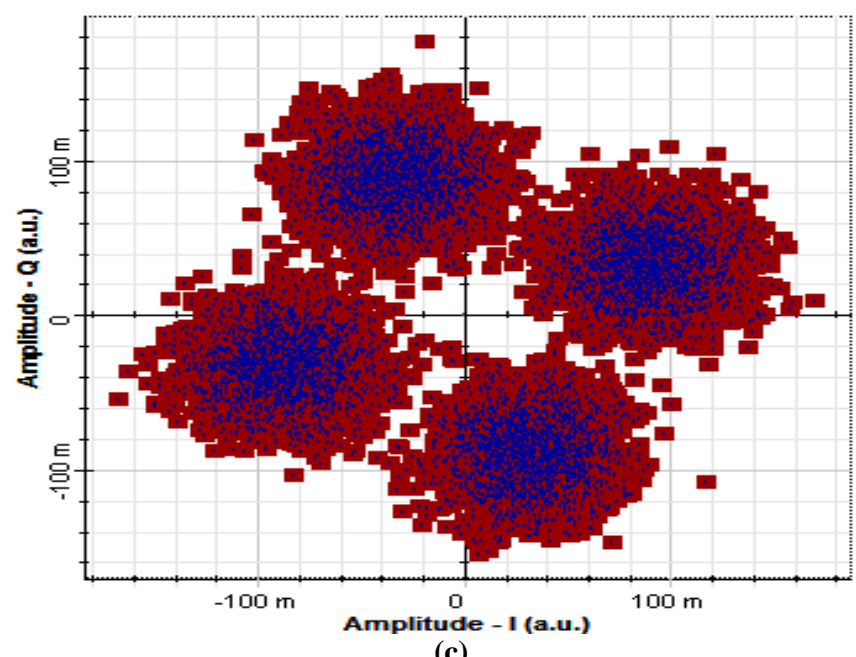

(c)

Fig 4: Measured Constellations under impact of transmitting pointing error (a) At $1 \mu \mathrm{rad}$ (b) At 3 $\mu \mathrm{rad}(\mathrm{c})$ At $4 \mu \mathrm{rad}$ 


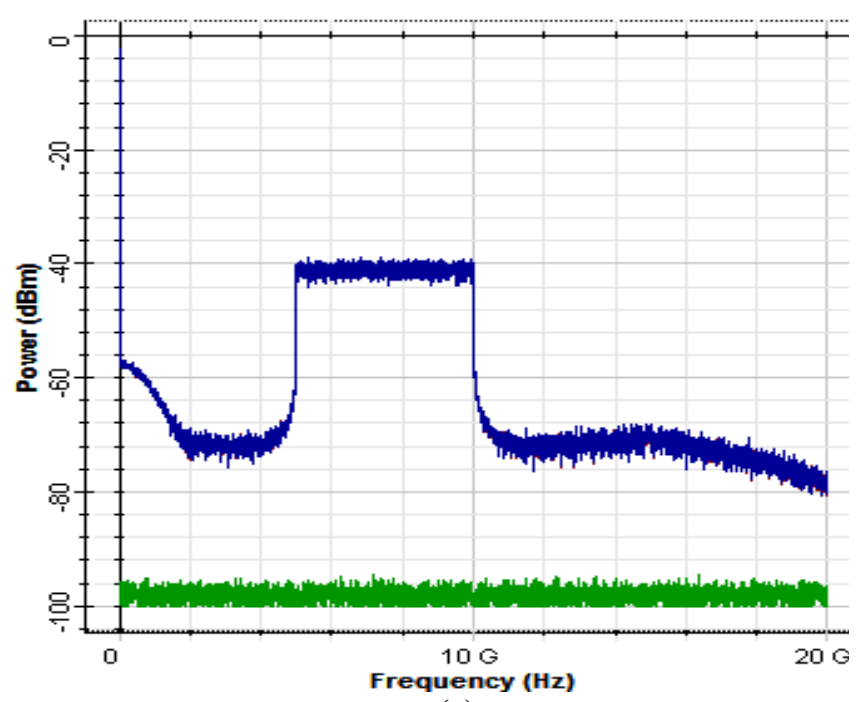

(a)

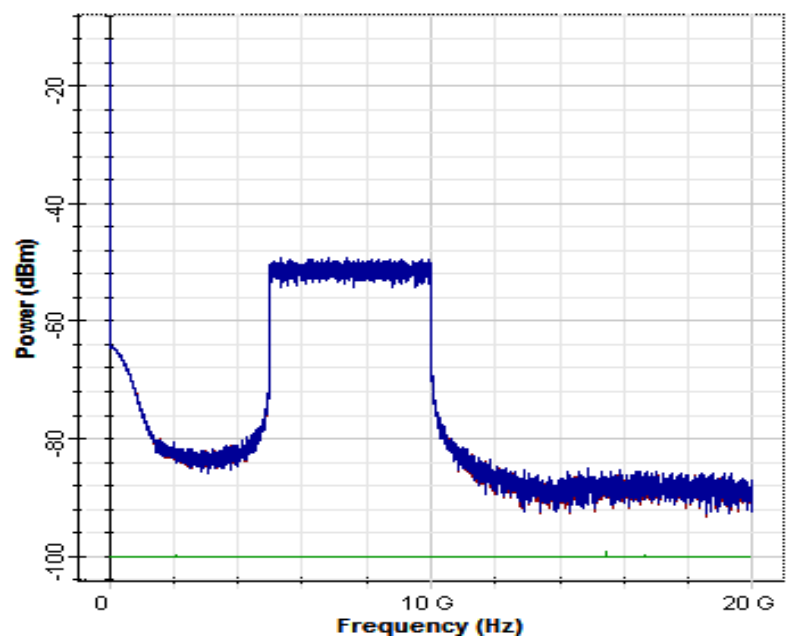

(b)

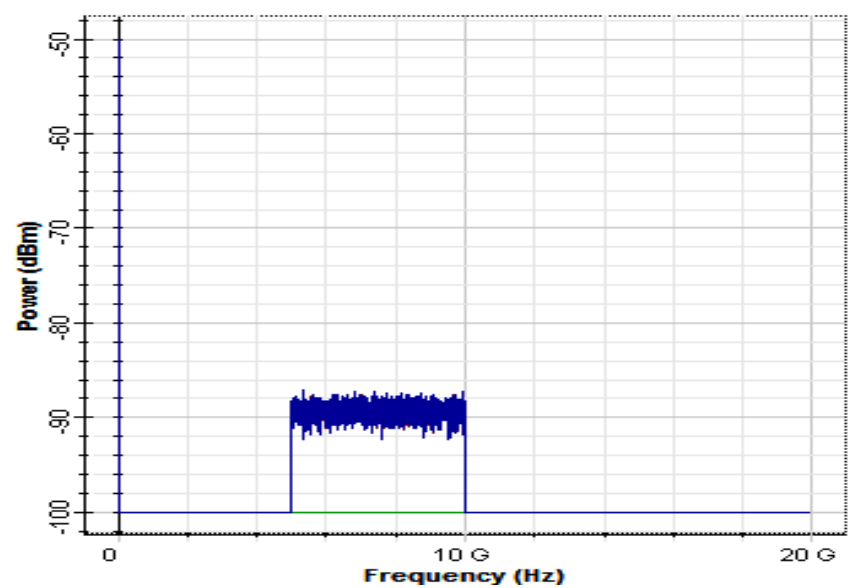

(c)

Fig 5: Measured RF Spectrums under impact of transmitting pointing error (a) At $1 \mu \mathrm{rad}$ (b) At 3 $\mu \mathrm{rad}(\mathrm{c})$ At $4 \mu \mathrm{rad}$

\section{CONCLUSION}

In this work, 10 Gbps data is transmitted over Is-OWC link having a span of $10,000 \mathrm{~km}$ by incorporating DPSK scheme followed by the OFDM technique. The reported result shows the successful transmission of $10 \mathrm{Gbps}$ data over $10000 \mathrm{~km}$ Is-OWC link with acceptable SNR and constellations under the impact of transmitting pointing errors.

\section{REFERENCES}

[1] J. Hecht, "Short History Of Laser Development," Optical Engineering, Vol. 49, Pp. 091002-091002-23, 2010.

[2] E. Lutz, M. Werner, And A. Jahn, Satellite Systems For Personal And Broadband Communications: Springer Science \& Business Media, 2012.

[3] S. Chaudhary And A. Amphawan, "The Role And Challenges Of Free-Space Optical Systems," Journal Of Optical Communications, Vol. 35, Pp. 327-334, 2014.

[4] S. Chaudhary And A. Sharma, "6 X 20gbps Long Reach Wdm-Pi Based High Altitude Platform Inter-Satellite Communication System," International Journal Of Computer Applications, Vol. 122, 2015.

[5] S. Chaudhary, A. Sharma, And N. Chaudhary, "6× 20 Gbps Hybrid Wdm-Pi Inter-Satellite System Under The Influence Of Transmitting Pointing Errors," Journal Of Optical Communications, Vol. 37, Pp. 375-379, 2016.

[6] S. Chaudhary And S. Sharma, "Role Of Turbulences In Wdm-Polarization Interleaving Scheme Based InterSatellite Communication System," International Journal Of Computer Applications, Vol. 104, 2014.

[7] S. Chaudhary, N. Chaudhary, S. Sharma, And B Choudhary, "High Speed Inter-Satellite Communication System By Incorporating Hybrid PolarizationWavelength Division Multiplexing Scheme," Journal Of Optical Communications.

[8] A. Amphawan, S. Chaudhary, And V. Chan, "2 X 20 Gbps-40 Ghz Ofdm Ro-Fso Transmission With Mode Division Multiplexing," Journal Of The European Optical Society-Rapid Publications, Vol. 9, 2014.

[9] A. Amphawan, S. Chaudhary, T. Elfouly, And K. Abualsaud, "Optical Mode Division Multiplexing For Secure Ro-Fso Wlans," Advanced Science Letters, Vol. 21, Pp. 3046-3049, 2015.

[10] S. Chaudhary And A. Amphawan, "High-Speed Millimeter Communication Through Radio-Over-FreeSpace-Optics Network By Mode-Division Multiplexing," Optical Engineering, Vol. 56, P. 116112, 2017.

[11] S. Chaudhary, A. Amphawan, And K. Nisar, "Realization Of Free Space Optics With Ofdm Under Atmospheric Turbulence," Optik-International Journal For Light And Electron Optics, Vol. 125, Pp. 5196-5198, 2014.

[12] V. Sharma, "High Speed Co-Ofdm-Fso Transmission System," Optik-International Journal For Light And Electron Optics, Vol. 125, Pp. 1761-1763, 2014.

[13] V. Sharma And S. Chaudhary, "Implementation Of Hybrid Ofdm-Fso Transmission System," International Journal Of Computer Applications, Vol. 58, 2012.

[14] V. Sharma And S. Kumar, "Empirical Evaluation Of Wired-And Wireless-Hybrid Ofdm-Ossb-Rof Transmission System," Optik-International Journal For Light And Electron Optics, Vol. 124, Pp. 4529-4532, 2013. 
[15] V. Sharma And S. Kumar, "Hybrid Ofdm-Ossb-Rof Transmission System Incorporating Fiber Bragg Grating," Optik-International Journal For Light And Electron Optics, Vol. 124, Pp. 4670-4672, 2013.

[16] D. Wake, M. Webster, G. Wimpenny, K. Beacham, And L. Crawford, "Radio Over Fiber For Mobile Communications," In Microwave Photonics, 2004. Mwp'04. 2004 Ieee International Topical Meeting On, 2004, Pp. 157-160.

[17] A. Amphawan And S. Chaudhary, "Free-Space Optical Mode Division Multiplexing For Switching Between Millimeter-Wave Picocells," In International Conference On Optical And Photonic Engineering (Icopen2015), 2015, Pp. 95242h-95242h-6.

[18] A. Amphawan, S. Chaudhary, And B. B Gupta, "Secure Mdm-Ofdm-Ro-Fso System Using $\mathrm{Hg}$ Modes," International Journal Of Sensors Wireless Communications And Control, Vol. 5, Pp. 13-18, 2015.

[19] S. Chaudhary And A. Amphawan, "High-Speed Millimeter Communication Through Radio-Over-FreeSpace-Optics Network By Mode-Division Multiplexing," Optical Engineering, Vol. 56, P. 116112, 2017.

[20] S. Chaudhary, A. Amphawan, And K. Nisar, "Realization Of Free Space Optics With Ofdm Under Atmospheric Turbulence," Optik-International Journal For Light And Electron Optics, Vol. 125, Pp. 5196-5198, 2014.

[21] V. Sharma, "High Speed Co-Ofdm-Fso Transmission System," Optik-International Journal For Light And Electron Optics, Vol. 125, Pp. 1761-1763, 2014.

[22] Rudrakshi Kapoor, Abhishek Sharma, Sushank Chaudhary, "Empirical Evaluation Of 4 Qam And 4 Psk In Ofdm-Based Inter-Satellite Communication System", Journal Of Optical Communications, Published Online: 2017-06-29 | Doi: Https://Doi.Org/10.1515/Joc-20170059 .

[23] Sharma, A., Chaudhary, S., Thakur, D., Dhasratan, Vigneswaran "A Cost-Effective High-Speed Radio Over Fibre System For Millimeter Wave Applications", Journal Of Optical Communications, Published Online: 2017-12-15 | Doi: Https://Doi.Org/10.1515/Joc-20170166

[24] Sushank Chaudhary, Priyanka Chauhan, Abhishek Sharma, "High Speed 4× 2.5 Gbps-5 Ghz Ami-Wdm-Rof Transmission System For Wlans", Journal Of Optical Communications, Published Online: 2017-07-18 | Doi: Https://Doi.Org/10.1515/Joc-2017-0082

[25] Sushank Chaudhary, Deepika Thakur, Abhishek Sharma, "10 Gbps-60 Ghz Rof Transmission System For 5 G Applications", Journal Of Optical Communications, Published Online: 2017-07-22 | Doi: Https://Doi.Org/10.1515/Joc-2017-0079
[26] Abhishek Sharma, Neha Chaudhary, Sushank Chaudhary, " $6 \times 20$ Gbps Hybrid Wdm-Pi Inter-Satellite System Under The Influence Of Transmitting Pointing Errors", Journal Of Optical Communications, Published Online: 2016-05-27 | Doi: Https://Doi.Org/10.1515/Joc2015-0099

[27] Abhishek Sharma, Neetu, "Analysis And Mitigation Of Receiver Pointing Error Angle On Inter-Satellite Communication" International Journal Of Innovative Technology And Research, Volume 3, Issue 6, Pages 2540-2544, Nov 2015

[28] Sushank Chaudhary, Abhishek Sharma, Neetu, "6 X 20gbps Long Reach Wdm-Pi Based High Altitude Platform Inter-Satellite Communication System" International Journal Of Computer Applications, Volume 122, Issue 22, Pages 41-45, July 2015

[29] Savita Rana Abhishek Sharma, "Comprehensive Study Of Radio Over Fiber With Different Modulation Techniques - A Review", International Journal Of Computer Applications, Volume 170, Issue 4, Pages 2225, Aug 2017 Doi: 10.5120/Ijca2017914829

[30] Abhishek Sharma, Deepika Thakur, "A Review On Wlans With Radio-Over-Fiber Technology", International Journal Of Electronics And Communication Engineering (Ijece), Volume 6, Issue 5, Pages 1-6, Aug 2017.

[31] Kanika Thakur Abhishek Sharma, "Comparison Of Mdrz, Csrz And Drz Schemes Using Different Communiation Channels", International Journal Of Computer Applications, Aug 2017 Doi: 10.5120/Ijca2017915106

[32] Kanika Thakur Abhishek Sharma, "Study Of Radio Over Fiber With Different Coding Channel - A Review", International Journal Of Computer Applications, Aug 2017, Doi: 10.5120/Ijca2017915033

[33] Abhishek Sharma, Priyanka Chauhan, "A Study Of Radio Over Fiber Technology In Wlan Applications" International Journal For Research In Applied Science \& Engineering Technology (Ijraset) Volume 5 Issue Viii, Page 416-420, August 2017

[34] Abhishek Sharma, Rudrakshi Kapoor, "Study Of Various Challenges In Is Owc: A Review", International Journal For Research In Applied Science \& Engineering Technology (Ijraset) Volume 5 Issue Viii, Page 802-807, August 2017

[35] Abhishek Sharma, Savita Rana, "Implementation Of Radio Over Fiber Technology With Different Filtration Techniques" International Journal For Research In Applied Science \& Engineering Technology (Ijraset) Volume 5 Issue Viii, Page 783-789, August 2017. 